\title{
Assessment of Knowledge of Pregnant Mothers on Maternal Nutrition and Associated Factors in Guto Gida Woreda, East Wollega Zone, Ethiopia
}

\section{Gemeda Daba, Fekadu Beyene, Habtamu Fekadu* and Wondu Garoma}

Wollega University, Ethiopia

\begin{abstract}
Nutrition is a fundamental pillar of human life and its requirement varies with respect to age, gender and during physiological changes such as pregnancy. The aim of this study was to assess the knowledge of pregnant mothers on maternal nutrition and associated factors in Guto Gida Woreda, East Wollega Zone, Ethiopia during January to June of the year 2013, and using quantitative cross-sectional descriptive study on a sample of 422 pregnant women and supplemented by qualitative study (focus group discussion).

The quantitative data were analyzed using SPSS for windows version (16.0). Multiple logistic regression was run to assess factors that were associated with the dependent variable at $p<0.05$ and to control the confounders. This research showed only $64.4 \%$ of women had nutrition knowledge during pregnancy. There was a positive significant relation between information about nutrition, educational status of mothers and family income and nutrition knowledge of mothers during pregnancy $(p<0.001)$. The knowledge of pregnant mothers was relatively low in this study. Information about nutrition, family income and educational status of mothers had a positive significant relation with mothers' nutrition knowledge in the study area. Hence, the government in collaboration with concerned bodies should focus on nutritional education and information about nutrition to increase the knowledge of pregnant mothers on nutrition and put in practice during pregnancy in the study area.
\end{abstract}

Keywords: Knowledge; Maternal nutrition; Pregnancy; Guto Gida Woreda

\section{Introduction}

All human beings need a balanced amount of nutrients for proper functioning of the body system. Nutrition is a fundamental pillar of human life, health and development throughout the entire life span [1]. Proper food and good nutrition are essential for survival, physical growth, mental development, performance and productivity, health and wellbeing. However, the nutrition requirement varies with respect to age, gender and during physiological changes such as pregnancy. Pregnancy is such a critical phase in a woman's life, when the expecting mother needs optimal nutrients of superior qualities to support the developing fetus. Naturally, the urge to eat more is experienced by nearly all pregnant women [1].

Pregnancy is considered to be a delightful experience for the expectant mother. Evidences manifested that adequate intake of nutrition is a key component for individual's health and well-being, particularly during pregnancy [2]. It is well documented that inadequate maternal nutrition results in increased risks of short term consequences such as; Intra Uterine Growth Restriction (IUGR), low birth weight, preterm birth, prenatal and infant mortality and morbidity. Moreover, excessive intake of nutrients during pregnancy can lead to some pregnancy complications (such as, preeclampsia and gestational diabetes, macrosomia, distocia and higher prevalence of cesarean section) [2]. On the other hand, as the long run outcomes, inadequate intake of nutrients were found to have pathophysiologic or metabolic depict that will appear as disorders of child growth and development as well as adult chronic disease after a long period of quiescence [2].

Eating well during pregnancy means do more than simply increase how much the mother eats. The mother must also consider what she eats. The ability of mother to provide nutrients and oxygen for her baby is a critical factor for fetal health and its survival [3]. Failure in supplying the adequate amount of nutrients to meet fetal demand can lead to fetal malnutrition. The fetus responds and adapts to under nutrition but by doing so it permanently alters the structure and function of the body.
Maternal over nutrition also has long-lasting and detrimental effects on the health of the offspring [3].

Malnutrition is one of the most serious health problems affecting children and their mothers in Ethiopia. Undernourished mothers face greater risks during pregnancy and childbirth, and their children set off on a weaker developmental path, both physically and mentally. Undernourished children have lower resistance to infection and are more likely to die from common childhood ailments as diarrheal diseases and respiratory infections [4]. Those who survive may be locked into a vicious cycle of recurring sickness and faltering growth, often with irreversible damage to their cognitive and social development. Malnutrition prevents individuals and even the whole country from achieving full potential, and is closely related with survival, poverty and development [4].

The incidence of dietary inadequacies as a result of dietary habits and patterns in pregnancy is higher during pregnancy than at any other stage of the life cycle [5]. It was shown that, nutrition knowledge was predictive of change in dietary habits and health advices encouraged expectant women to advance their food intake [6].

Several study including [7] has indicated that the correlation between poor maternal nutritional status and adverse birth outcomes is complex and are influenced by many biologic, socioeconomic, and demographic factors, which vary widely in different populations [7].

${ }^{*}$ Corresponding author: Habtamu Fekadu, Wollega University, Ethiopia, E-mail fekadu_habtamu@yahoo.com

Received September 19, 2013; Accepted November 18, 2013; Published November 22, 2013

Citation: Daba G, Beyene F, Fekadu H, Garoma W (2013) Assessment of Knowledge of Pregnant Mothers on Maternal Nutrition and Associated Factors in Guto Gida Woreda, East Wollega Zone, Ethiopia. J Nutr Disorders Ther 3: 130. doi:10.4172/2161-0509.1000130

Copyright: ( 2013 Daba G, et al. This is an open-access article distributed unde the terms of the Creative Commons Attribution License, which permits unrestricted use, distribution, and reproduction in any medium, provided the original author and source are credited. 
It is therefore, the promotion of women's health and other preventive health care practice should start before birth, during intrauterine life and extends throughout different phases of their lives in order to sustain their reproductive health in general [8]. The importance of maternal nutrition during pregnancy has long been recognized. The National Academy of Science in America issued a report that reviewed studies of reproductive experience concluded that adequate prenatal nutrition was one of the most important environmental factors affecting the health of pregnant women and their babies [8].

\section{Statement of the Problem}

According to UNICEF (2009), each year, more than half a million women die from causes related to pregnancy and childbirth. Nearly 4 million newborns die within 28 days of birth (UNICEF, 2009) [9]. Many of the 200 million women who become pregnant each year, most of them in developing countries, suffer from ongoing nutritional deficiencies [10], repeated infections [11] and the long term cumulative consequences of under nutrition during their own childhood [10].

Many women suffer from a combination of chronic energy deficiency, poor weight gain in pregnancy, anemia, and other micronutrient deficiencies, as well as infections like HIV and malaria. These along with inadequate obstetric care, contribute to high rates of maternal mortality and poor birth outcomes [12].

Maternal under-nutrition diminishes a woman's productivity, causing repercussions for herself, her family, her community, and the broader society [13]. Maternal malnutrition is influenced not only by lack of adequate nutrition but also influenced by factors like socio demographic factors, nutritional knowledge of mothers during pregnancies [13].

Although, researches and projects focused on maternal health are common, projects and researches focused specifically on maternal nutrition are rare [12] in the study area. Research, program reports, and other materials specifically related to maternal nutrition principles, practices, and programs are not abundant either in the study area.

Even though, maternal nutrition during pregnancy is crucial in reducing maternal mortality and infant mortality which are the target area in achieving millennium development goal, no study has been conducted to assess the knowledge of mothers on nutrition and associated factors during pregnancy in the study area. As a result, there is lack of comprehensive information regarding nutritional knowledge and factors associated with it in the study area.

\section{Objectives}

\section{General objective}

The general objective of the study was to assess the knowledge of pregnant mothers on maternal nutrition and associated factors in Guto Gida Woreda, East Wollega Zone, Ethiopia

\section{Specific objectives}

- To assess knowledge of pregnant mothers with regard to nutrition in the study area.

- To identify associated factors of nutritional knowledge of mothers during pregnancy in the study area (Figure 1).

\section{Materials and Methods}

\section{Description of the study area}

The study was conducted in Guto Gida Woreda which is found

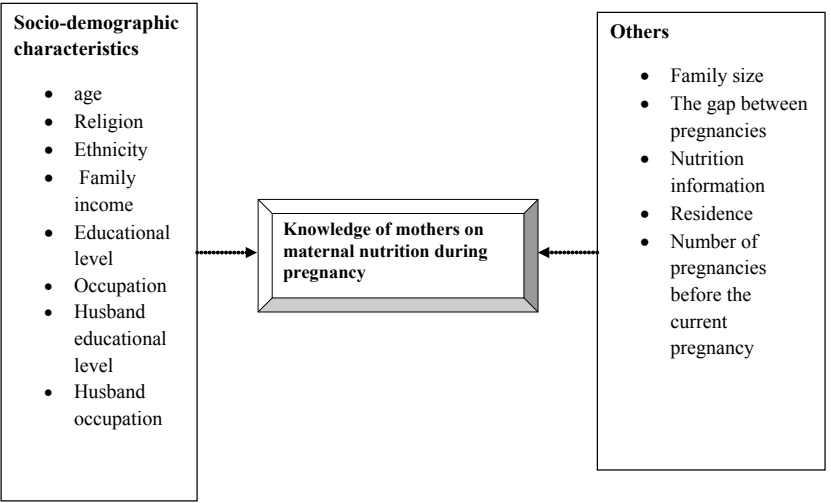

Figure 1: Conceptual frame model used in the study.

in East Wollega zone, Oromia regional state, Ethiopia. The woreda is divided in to 21 farmers associations and one urban center. The woreda is divided in to three distinct Agro-ecological areas: namely, highland, midland and lowland with the proportional of 0.26 percent, 46.74 percent and 53.00 percent respectively.

According to the information from Guto Gida Woreda health office (population and housing census conducted in 2007 G.C), the total population in the woreda was 105,332 in 2005 E.C out of which $97.22 \%$ of the total populations were living in rural area directly engaged their life agriculture. In 2005 E.C. (2013G.C) the total numbers of pregnant women were 3897 in the woreda.

Furthermore, According to the information from Guto Gida Woreda health office during data collection there were two health centers and 24 health posts under government ownership providing health services for the community in the woreda.

\section{Study designs}

A cross-sectional descriptive institutional based study was conducted to assess knowledge of women about maternal nutrition and factors associated with it during pregnancy that employed both quantitative and qualitative data collection method during January to June of the year 2013.

\section{Source population}

All Pregnant women who visited Guto Gida health centers or health posts antenatal care fellow up during January to June of the year 2013.

\section{Study population}

Sampled pregnant women who visited Guto Gida health centers and health posts for antenatal care during January to June of the year 2013.

\section{Sample Size Determination}

\section{Qualitative method}

For the qualitative study Focus Group Discussion (FGD) was carried out by purposively selected groups of pregnant women that were not participated in the quantitative study from the same areas.

\section{Quantitative method}

The sample size was determined by the assumption that $50 \%$ of the pregnant mothers were not knowledgeable on maternal nutrition 
during pregnancy with $5 \%$ marginal error and $95 \% \mathrm{CI}$ and a none response rate of $10 \%$. Based on this assumption, the actual sample size for the study was determined using the formula for single population proportion.

$$
n=\frac{\left(Z_{\alpha / 2}\right)^{2} p q}{d^{2}}
$$

Where $\mathrm{n}=$ Sample size

$\mathrm{Z}=\mathrm{Z}$ value corresponding to a $95 \%$ level of significance $=1.96$

$\mathrm{p}=$ expected proportion of knowledge, attitude and practice of mothers on nutrition during pregnancy $=50 \%=0.5$

$$
\begin{aligned}
& \mathrm{q}=(1-\mathrm{p})=(1-0.5)=0.5 \\
& \mathrm{~d}=\text { absolute precision }(5 \%)
\end{aligned}
$$

None response rate $=10 \%$

Therefore, from the above sample size is:

$$
n=\frac{1.96^{2} \times 0.5 \times 0.5}{0.05 \times 0.05}
$$

$\mathrm{n}=384+38=422$

\section{Sampling Procedure}

\section{Quantitative method}

The calculated sample size was proportionally allocated to the randomly selected health center and health posts from Guto Gida Woreda based on the average number of client prior to the study period in the respective antenatal care fellow units. Then to select study subjects from each antenatal care unit, systematic sampling was applied by referring client's registration book for a month prior to data collection. It was from these numbers that every $\mathrm{k}^{\text {th }}$ person as they registered was included in the sample at each antenatal care unit until the desired sample size was attained.

\section{Data collection procedures}

A Semi-structured questionnaires prepared in English language were translated in to Afan Oromo and then translated back to English to check for consistency. In addition, focus group discussions were used for the qualitative study. The questionnaires were pre- tested in Nekemte health center antenatal care unit. The pre-test were done on $5 \%$ of the total sample size. The questionnaire was then assessed for its clarity, length and completeness.

\section{Data Collection}

\section{Qualitative data}

Focus group discussions at two sites were carried out with each participating six members of pregnant women along with principal investigator. Finally, the information was tape recorded to support the field notes used during discussion.

\section{Quantitative data}

For administering the semi-structured questionnaire, four health professionals who had diploma were recruited to conduct an interview. Training was given for two days (including half day of pretest) on the objective, relevance of the study, confidentiality of information, respondent's right, informed consent and techniques of interview. One supervisor who has fist degree was assigned to supervise the data collection.

\section{Variables}

\section{Dependent variable}

- Knowledge of pregnant mothers about maternal nutrition.

\section{Knowledge of pregnant mothers about maternal nutrition}

Under the construct of nutrition knowledge, there were thirteen questions for quantitative study. Nutrition knowledge questions aimed in assessing nutrition knowledge of pregnant women on the aspects of nutrition required during pregnancy. The questions assessed respondents' knowledge which was assumed to be measured through the following questions:

- Definition of food

- The good balanced diet

- Importance of food or Proper nutrition during pregnancy

- The pregnant diet differs than other diet.

- Sources of protein, carbohydrate, iron, iodine and vitamin A

- Negative consequences of malnutrition for the mother and the baby

- Husband or other family members influence and decision on the type and frequency of taking food in the current pregnancy

Accordingly, respondents were allowed to choose correct answers by indicating whether a given statement was yes or no. Finally, the knowledge of respondents on nutrition were scored and computed for the nutrition knowledge variables. One point was allocated to a correct response for all questions of nutrition knowledge in which the correct answers summed together (the sum of the total scores for nutrition knowledge varied from ( 0 up to 13 ) points maximum score) and converted out of 100 .

\section{Independent (determinant) variable}

- Socio-demographic characteristics

- Nutrition information and residence

\section{Data Quality Assurance}

Quality issues were addressed through the following measures to ensure that the data generated was complete, reliable, accurate and above all reproducible using the same methods. These measures contribute towards both internal and external validity of the study.

To ensure the quality of data, training of data collectors and supervisors were undertaken and administration of pre-test among 5\% of the total sample size to assessed its clarity, length, completeness and consistency. The questionnaires were also translated in to local language to facilitate understanding of the respondents.

\section{Data Analysis}

The data were cheeked, cleared and entered into SPSS data sheet software and analysis was done by using SPSS version (16.0). The descriptive analysis such as proportions, percentages, frequency distribution and measures of central tendency were used.

Initially, bi-variable analysis was performed between knowledge of mothers on nutrition during pregnancy (dependent variable) and each of the potential factors associated with knowledge of mothers on nutrition during pregnancy (independent variables), one at a time. 
Citation: Daba G, Beyene F, Fekadu H, Garoma W (2013) Assessment of Knowledge of Pregnant Mothers on Maternal Nutrition and Associated Factors in Guto Gida Woreda, East Wollega Zone, Ethiopia. J Nutr Disorders Ther 4: 130. doi:10.4172/2161-0509.1000130

Their Odds Ratios (OR) at 95\% Confidence Intervals (CI) and p-values was obtained. The findings at this stage helped us to identify important associations.

Then multivariable analysis was performed using the logistic regression model. Factors that were significantly associated with knowledge of mothers on nutrition during pregnancy at bivariate analysis and those not significant but with previous evidence from literature review indicating possible association with knowledge of mothers on nutrition during pregnancy was considered in multivariate logistic regression model.

\section{Ethical Considerations}

Ethical clearance and permission were obtained from Wollega University Ethical Review Committee and permission was secured from Guto Gida Woreda health office. The nature of the study was fully explained to the study participants to obtain their oral informed consent prior to participation in the study and data was kept confidential. Informed consent was obtained from each respondent before interview.

\section{Operational Definition}

\section{Knowledge}

Is awareness and understanding that one has gained on nutrition during pregnancy through learning and practice and pregnant women was considered to be knowledgeable if she correctly answered greater than or equal to $70 \%$ of the total knowledge assessing questions.

\section{Maternal nutrition}

Refers to the nutritional needs of women during the antenatal and postnatal period (i.e., when they are pregnant and breastfeeding) and also may refer to the pre-conceptual period (i.e., adolescence).

\section{Pregnancy}

Is state of carrying a developing embryo or fetus within the female body from a period of fertilization to delivery.

\section{Result and Discussion}

\section{Result}

Socio-demographic characteristics: Out of the 422 sampled pregnant women to be included in this study 419 responded to the questionnaires making a response rate of $99.3 \%$. Different questions were asked to assess knowledge of pregnant mothers on nutrition and determinant factors in the study area. The mean age $( \pm$ SD) of the participants was $24.7( \pm 5.12)$ years, while the age range was 16-38. However, considerably high proportions of the respondents $(48.2 \%)$ were in the age range of 15-24 years. Besides, most study respondents were married (97.1\%).

Regarding the ethnic composition and religion of the respondents about greater than three quarter of them were Oromo and the majority of respondents' religion was protestant followed by Orthodox as shown in the Table 1 below.

As far as education level of study population is concerned, almost two third $(65.4 \%)$ of the respondents were illiterate. Concerning the occupation of respondents, the majority $(85.7 \%)$ were house wives. Greater than three quarter $(89.8 \%)$ of the respondents husbands occupation were farmer, whom above half $(52 \%)$ of their educational status were illiterate as described in Table 1 below.
On the other way regarding women's estimated monthly income majority of women $(79.0 \%)$ earned less than 1000 birr per month, (10.0\%) of them earned 1000-2000 birr per month and only (11.0\%) of the respondents had monthly income greater than 2000 birr.

As far as residence and nutrition information during pregnancy are concerned, about (95.7\%) of the respondents were living in rural and only $(57.8 \%)$ of the respondents had nutritional information during their pregnancy as here presented in Table 1 below.

On the other hand, twelve pregnant women participated in focus group discussion for qualitative study. Their age ranges from 20-35 years. Most respondents were married while ten of them were house wife. Eight of the respondents were illiterate while four of them had attended at least primary education.

Knowledge of mothers on maternal nutrition during pregnancy: The findings from quantitative focus group discussion data analysis revealed that: Only two of the respondents mentioned the main food groups and common sources of protein, carbohydrate, iron, iodine and vitamin A even though most of the respondents described the importance of foods in different ways during pregnancy. Most respondents raised an idea that family member did not influenced and decided on the type and frequency of their food.

"27 year old pregnant women said that food not only during pregnancy but also during non-pregnancy is important for many purposes for

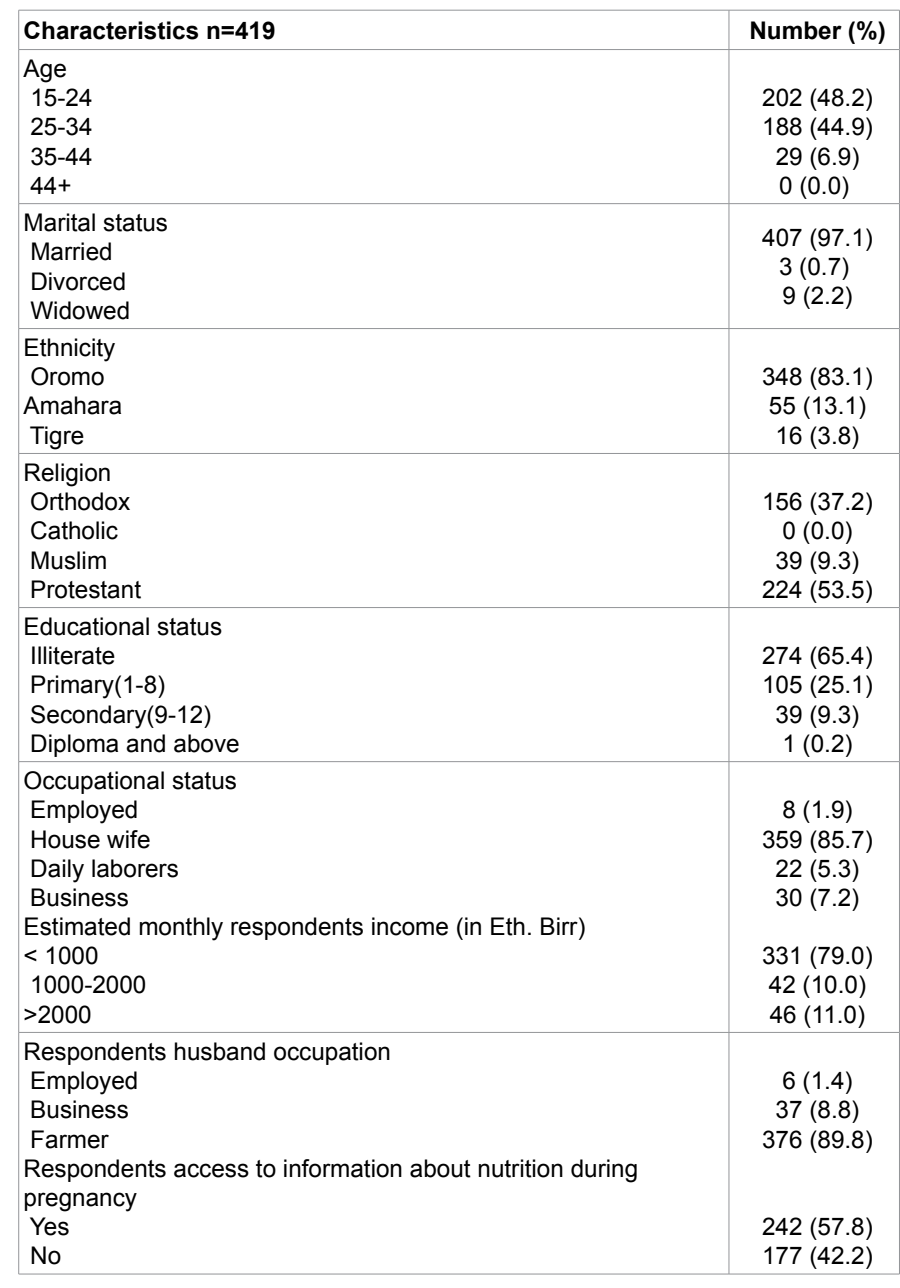

Table 1: Socio-demographic characteristics of study participants. 
Citation: Daba G, Beyene F, Fekadu H, Garoma W (2013) Assessment of Knowledge of Pregnant Mothers on Maternal Nutrition and Associated Factors in Guto Gida Woreda, East Wollega Zone, Ethiopia. J Nutr Disorders Ther 4: 130. doi:10.4172/2161-0509.1000130

example for healthy living. But I do not know the meaning and common sources of protein, carbohydrate, iron, iodine and vitamin A."

"A 35 years pregnant woman said that the amount and frequency foods during pregnancy and before pregnancy in my house and nearby are not different. I worry about foods sufficiency to the family members especially those who are engaged in agricultural activities because they are always on work."

Out of 419 respondents responded for quantitative study,(52.5\%), $(50.6 \%),(72.3 \%)$, and $(71.8 \%)$ of the respondents had the knowledge that food during pregnancy is important for bodies energy and heat, proper functioning of the body, growth and development of the fetus and infection fighting respectively. However, (47.5\%), (49.4\%), (27.7\%) and $(28.2 \%)$ of the respondent did not know the importance of food during pregnancy for bodies energy and heat, proper functioning of the body, growth and development of the fetus and infection fighting respectively as indicated in Table 2 below.

Concerning the respondents knowledge about the meaning of food, only (42.2\%) of the respondents knew and correctly answered the meaning of foods while $(57.8 \%)$ of the respondents did not know the meaning of food.

Regarding to the main food group or balance diet question offered to respondents to assess their nutritional knowledge, majority (74.0\%) of the respondents did not knew the main food groups or the balance diet while $(26.0 \%)$ of the respondent knew about the main food groups or the balance diet.

Concerning the nutritional knowledge of the respondents about some common food sources of nutrients, most respondents $(70.6 \%)$, (79.0\%), (80.7\%), (78.3\%) and (88.1\%) had no knowledge about common food sources of protein, carbohydrate, iron, vitamin $\mathrm{A}$ and iodine respectively. But the rest (29.4\%), (21\%), (19.3\%), (21.7\%) and (11.9\%) had the knowledge about common food sources of protein, carbohydrate, iron, vitamin A and iodine respectively as listed in Table 2 below.

As described in Table 2 below, regarding to the inadequate nutrition during pregnancy, only (34.8\%) respondents responded that inadequate nutrition during pregnancy can be the cause of miscarriage or preterm birth whereas (65.2\%) respondents did not know whether or not inadequate nutrition during pregnancy can be the cause of miscarriage or preterm birth (Table 2 ).

In general, up on the answers given by the respondents to the knowledge assessing questions $64.4 \%$ of the respondents were found to

\section{be knowledgeable about nutrition during pregnancy.}

Associated factors of nutritional knowledge of mothers during pregnancy: In this study the bivariate analysis showed that husband educational level had significant association with nutrition knowledge during pregnancy $(\mathrm{p}<0.05)$. More over in bivariate analysis, age, educational status of mothers, family income, information about nutrition during pregnancy, number of pregnancy before the current pregnancy and gap between pregnancies had strong statistical association with the knowledge of mothers on nutrition during pregnancy $(\mathrm{p}<0.001)$ whereas, family size and residence of the respondents have no association with the knowledge of mothers on nutrition during pregnancy $(\mathrm{p}>0.05)$.

After bivariate analysis, those predictors which showed statistical significance were used to run multivariate analysis. In a multivariate analysis, those who had an estimated monthly income of greater than 1000 birr were 5.7 times more likely knowledgeable about nutrition during pregnancy than who had an estimated monthly income of less than 1000 birr (AOR=5.67, 95\% CI: 2.08-15.44) and also those respondents who had an estimated monthly income of greater than 2000 birr were 6.0 times more likely knowledgeable about nutrition during pregnancy than who had an estimated monthly income of less than 1000 birr (AOR=5.93, 95\% CI: $1.67-21.31)$ as indicated in Table 3 below.

In addition, in a multivariate analysis educational status of woman displayed significant positive relationships with a woman's odds of nutrition knowledge during pregnancy $(\mathrm{p}<0.01)$. Relative to women with no education, women with primary education had significantly greater odds of nutrition knowledge during pregnancy $(\mathrm{AOR}=3.09$, 95\% CI: 1.63-5.86)

On further multivariate analysis age of respondent, husband educational level, number of pregnancies before the current pregnancy and gaps between pregnancies didn't show significant association with knowledge of mothers on nutrition during pregnancy. The finding of the study identified that information about nutrition during pregnancy have strong statistical association with nutrition knowledge of mothers during pregnancy $(\mathrm{p}<0.001)$. In multivariate analysis those women who had information about nutrition were 3.6 times more likely knowledgeable about nutrition as compared to the pregnant women with no information about nutrition during pregnancy $(\mathrm{AOR}=3.59$, 95\%CI: 2.03-6.35) as shown in the Table 3 below.

${ }^{* * *}=\mathrm{P}<0.001$ (strong statistical association), ${ }^{* *}=\mathrm{P}<0.01$ (statistical association),

\begin{tabular}{|c|c|c|}
\hline \multirow[t]{2}{*}{ Knowledge indicators $n=419$} & \multicolumn{2}{|c|}{ Response in number (\%) } \\
\hline & Yes & No \\
\hline Knowledge about the meaning of food & $177(42.2)$ & $242(57.8)$ \\
\hline Importance of food for growth and development of fetus & $303(72.3)$ & $116(27.7)$ \\
\hline Importance of food for bodies heat and energy & $220(52.5)$ & $199(47.5)$ \\
\hline Importance of food for proper functioning of the body & $212(50.6)$ & $207(49.4)$ \\
\hline Importance of food for infection fighting & $301(71.8)$ & $118(28.2)$ \\
\hline $\begin{array}{l}\text { Knowledge about the main food groups or balance diet } \\
\text { Knowledge about food sources of protein } \\
\text { Knowledge about food sources of carbohydrates } \\
\text { Knowledge about food sources of iron } \\
\text { Knowledge about food sources vitamin A } \\
\text { Knowledge about food sources of iodine } \\
\text { Knowledge about inadequate nutrition can be the cause of miscarriage and/or preterm birth } \\
\text { Knowledge about husband or family member should not influence and decide on the type and frequency of taking food during } \\
\text { pregnancy }\end{array}$ & $\begin{array}{l}109(26.0) \\
123(29.4) \\
88(21.0) \\
81(19.3) \\
91(21.7) \\
50(11.9) \\
146(34.8) \\
192(45.8)\end{array}$ & $\begin{array}{l}310(74.0) \\
296(70.6) \\
331(79.0) \\
338(80.7) \\
328(78.3) \\
369(88.1) \\
273(65.2) \\
227(54.2)\end{array}$ \\
\hline
\end{tabular}

Table 2: knowledge characteristics of study participants of pregnant women. 
Citation: Daba G, Beyene F, Fekadu H, Garoma W (2013) Assessment of Knowledge of Pregnant Mothers on Maternal Nutrition and Associated Factors in Guto Gida Woreda, East Wollega Zone, Ethiopia. J Nutr Disorders Ther 4: 130. doi:10.4172/2161-0509.1000130

Page 6 of 7

\begin{tabular}{|c|c|c|c|c|}
\hline \multirow[t]{2}{*}{ Variables } & \multicolumn{2}{|c|}{ Knowledge } & \multicolumn{2}{|c|}{$95 \% \mathrm{Cl}$} \\
\hline & Yes & No & COR & AOR \\
\hline $\begin{array}{l}\text { Age category } \\
15-24 \\
25-34 \\
35-44 \\
44+\end{array}$ & $\begin{array}{c}148(73.3) \\
101(53.7) \\
21(72.4)\end{array}$ & $\begin{array}{c}54(26.7) \\
87(46.3) \\
8(27.6) \\
-\end{array}$ & $\begin{array}{c}1 \\
0.424(0.277-0.647)^{* * *} \\
0.958(0.400-2.290)\end{array}$ & $\begin{array}{c}1 \\
0.695(0.695-1.305) \\
2.621(0.794-8.655)\end{array}$ \\
\hline $\begin{array}{l}\text { Educational status } \\
\text { Illiterate } \\
\text { Primary(1-8grade) } \\
\text { Secondary(9-12) } \\
\text { Diploma and above } \\
\end{array}$ & $\begin{array}{c}144(52.6) \\
86(81.9) \\
39(100) \\
1(100)\end{array}$ & $\begin{array}{c}130(47.4) \\
19(18.1) \\
0 \\
0\end{array}$ & $\begin{array}{c}1 \\
\text { 4. } 086(2.356-7.06) * * * \\
- \\
-\end{array}$ & $\begin{array}{c}3.086(1.625-5.586) \\
- \\
-\end{array}$ \\
\hline $\begin{array}{l}\text { Estimated Monthly income } \\
<1000 \\
1000-2000 \\
>2000 \\
\text { Husband educ. level } \\
\text { Illiterate } \\
\text { Literate }\end{array}$ & $\begin{array}{l}196(59.2) \\
31(73.8) \\
43(93.5) \\
\\
125(56.6) \\
145(73.2)\end{array}$ & $\begin{array}{l}135(40.8) \\
11(35.3) \\
3(6.5 \\
\\
96(43.4) \\
53(26.8)\end{array}$ & $\begin{array}{c}1 \\
1.941(0.943-3.996) \\
9.872(3.001-32.476)^{* * *} \\
1 \\
2.035(1.346-3.078)^{*}\end{array}$ & $\begin{array}{c}1 \\
5.670(2.082-15.439)^{\star *} \\
5.948(1.660-21.307)^{\star *} \\
1 \\
1.332(0.989-1.394)\end{array}$ \\
\hline $\begin{array}{l}\text { Information about nutrition } \\
\text { No } \\
\text { Yes } \\
\text { No of pregnancy before the current } \\
\text { pregnancy } \\
\leq 2 \\
3-4 \\
\geq 5\end{array}$ & $\begin{array}{c}89(50.3) \\
181(74.8) \\
\\
172(72.9) \\
60(51.7) \\
38(56.7)\end{array}$ & $\begin{array}{l}88(49.7) \\
61(25.2) \\
64(27.1) \\
56(48.3) \\
29(43.3)\end{array}$ & $\begin{array}{c}1 \\
2.934(1.940-4.436)^{* * *} \\
1 \\
0.399(0.251-0.634)^{* * *} \\
0.488(0.278-0.855)\end{array}$ & $\begin{array}{c}1 \\
3.594(2.033-6.352) * * * \\
1 \\
0.586(0.291-1.179) \\
0.975(0.407-2.336)\end{array}$ \\
\hline $\begin{array}{l}\text { Gap duration between pregnancies } \\
<2 \text { years } \\
\text { 2-5years } \\
>5 \text { years }\end{array}$ & $\begin{array}{c}79(86.8) \\
178(56.9) \\
13(86.7)\end{array}$ & $\begin{array}{c}12(13.2) \\
135(43.1) \\
2(13.3)\end{array}$ & $\begin{array}{c}1 \\
0.20(0.105-0.383) * * * \\
0.987(0.198-4.928)\end{array}$ & $\begin{array}{c}1 \\
0.975(0.407-2.336) \\
1.314(0.208-8.317)\end{array}$ \\
\hline
\end{tabular}

$* * *=P<0.001$ (strong statistical association), $\quad * *=P<0.01$ (statistical association),

${ }^{*}=\mathrm{P}<0.05$ (statistically significant), COR: Crude Odds Ratio, AOR: Adjusted Odds Ratio

Table 3: Multivariable of nutrition knowledge by socio-demographic of study participants.

${ }^{*}=\mathrm{P}<0.05$ (Statistically Significant); COR: Crude Odds Ratio; AOR: Adjusted Odds Ratio

\section{Discussion}

Knowledge of mothers on maternal nutrition during pregnancy: This study has documented the level of knowledge of mothers during pregnancy on nutrition and associated factors in Guto Gida Woreda, East Wollega zone, Ethiopia. The incidence of dietary inadequacies as a result of dietary habits and patterns in pregnancy is higher during pregnancy than at any other stage of the life cycle [5]. It was shown that, nutrition knowledge was predictive of change in dietary habits and health advices encouraged expectant women to advance their food intake [6].

This study revealed that more than half (57.8\%) of the respondents did not know the meaning of food. This study result was in agreement with the study reported from Americaat El-Menshawy Hospital that about half of women didn't have enough knowledge regarding the meaning, the importance, and the constituents of a well-balanced diet for the pregnant women [14].

This study also pointed out that the nutritional knowledge of pregnant women about the importance of food during pregnancy as: (52.5\%), (50.6\%), (72.3\%) and (71.8\%) had the knowledge that food during pregnancy is important for bodies energy and heat, proper functioning of the body, growth and development of the fetus and fighting infection respectively in which the figure is slightly greater than the study conducted in Malawi, lilongwe, that most of the women $(60 \%)$ said that eating from all food groups is good for a woman's health and for foetal growth and development [15].
Most (74.0\%) of the respondents did not know the main food groups or the balance diet were as $(26.0 \%)$ of the respondent knew about the main food groups or the balance diet in the present study. The result of this study was lower than the study conducted in America that more than half of women in the study lacked the basic and the essential knowledge regarding the importance and sources of most of the types of vitamins and minerals [14]. This can be attributed to the fact that women lack better access to information about nutrition during pregnancy because they were housewives in the study area.

Although the knowledge about importance of food during pregnancy was high in this study, the knowledge about the common food source of protein, carbohydrates and most important minerals and vitamin was lower ((29.4\%), (21\%), (19.3\%), (21.7\%) and (11.9\%) knowledge about common food sources of protein, carbohydrate, iron, vitamin A and iodine respectively) than reported by [14] in which for example $61.3 \%$ of pregnant mother had good knowledge about the sources of iron and $71.8 \%$ knew the sources of calcium during pregnancy. The common food sources mentioned by respondents who knew about common food source of iron in this study were: teff (74\%), animal source (25\%) and others (1\%). The low nutritional knowledge level of common food sources may be due to low nutritional awareness or nutrition information and low socio economy of the study participants in this study.

Findings from qualitative focus group discussion emphasize the same with quantitative study where by: only two of the respondents mentioned the main food groups and common sources of protein, carbohydrate, iron, iodine and vitamin A even though most of the respondents described the importance of foods in different ways during pregnancy. 
Citation: Daba G, Beyene F, Fekadu H, Garoma W (2013) Assessment of Knowledge of Pregnant Mothers on Maternal Nutrition and Associated Factors in Guto Gida Woreda, East Wollega Zone, Ethiopia. J Nutr Disorders Ther 4: 130. doi:10.4172/2161-0509.1000130

This study revealed that only less respondents $(34.8 \%)$ had the knowledge that inadequate nutrition during pregnancy can be the cause of miscarriage or preterm birth which is in agreement with the study conducted in America at El-Menshawy Hospital in which the women in the study lacked the awareness of the consequences of inadequate nutrition during pregnancy on mother and fetus [14].

In general, up on the answers given by the respondents to the knowledge assessing questions this study pointed out $64.4 \%$ of the respondents were found to be knowledgeable about nutrition during pregnancy. This figure is lower than the study conducted in Malawi by Naomi, (2010) in which above two thirds (70\%) of the pregnant women had knowledge on nutrition and food groups in pregnancy [15]. This low nutritional knowledge may be due to low income, lack of information about nutrition during pregnancy and low educational status of the study participants in this study.

Associated factors of nutritional knowledge of mothers during pregnancy: In multivariate analysis age was not important predictor of knowledge of pregnant women in the study area. The finding of the study is not similar with findings from Accra, Ghana; in which women aged 25-35 years had higher mean percentage of nutritional knowledge, compared to those younger than 25 years and above [16]. The probable reason for observed discrepancy may be the difference in socio-cultural of the two-study population with respect to food and exposure to nutrition information during pregnancy.

Educational level, monthly income and nutrition information during pregnancy were identified as important predictors of knowledge of women on nutrition during pregnancy among the study participants in multivariate analysis. Similar study conducted in Malaysia demonstrated that individuals with better nutritional knowledge levels are significantly higher in educational level, nutritional attitude and occupational status. The finding of the study stated that individuals with a higher educational level had better nutrition knowledge and higher nutrition knowledge of employed women in study may be explained by more access to internet, books and magazines as source of information in work area [17].

The finding of this study identified that information about nutrition during pregnancy have strong statistical association with nutrition knowledge of mothers during pregnancy $(\mathrm{p}<0.001)$. In multivariate analysis those women who had information about nutrition were significantly greater odds nutrition knowledge compared to the pregnant women with no information about nutrition during pregnancy $(\mathrm{AOR}=3.594,95 \% \mathrm{CI}: 2.033-6.352)$.

Moreover, the most significant predicting factors for knowledge in this study were information about nutrition during pregnancy followed by women education level and family income. This result supported by the fact that good knowledge about basic nutrients and adequate well balanced diet usually resulting in positive dietary practices which are important determinants of optimum health from conception until death [18].

\section{Conclusion and Recommendation}

Based on the findings of the present study, it can be concluded that pregnant women had low-level of nutritional knowledge in the study area. There was significant positive relation between level of education, monthly income and nutrition information during pregnancy and nutrition knowledge. Hence, nutrition intervention such as nutrition education in different villages, health centers, and health posts and women organizations should be given for the community particularly for the pregnant mothers concerning nutrition during pregnancy to increase the nutritional knowledge of mothers in the study area.

\section{References}

1. World Bank (2006) Repositioning Nutrition as central to development: A strategy for large scale action, The International Bank for Reconstruction and Development, World Bank, Washington DC.

2. Luigi R, Orbitello B, Perini L, Pera V, Ciano R, et al. (2005) Effects of pregnancy on eating attitudes and disorders. A prospective study. J Psychosom Res 59 $175-179$.

3. Maynord K, Westenbey L (2003) Aboriginal teenage pregnancies compared with non-aboriginal in South Australia. Aust N Z J Obestet Gynaecol 42: 187 192

4. IYCN (2011) Infant \& Young Child Nutrition Project; Literature Review Prepared for the Message and Materials Development Workshop produced through support provided by the United States Agency for International Development (USAID), Addis Ababa, Ethiopia January 2011

5. Rao A, Sahoo S, Basumati P (2006) A study of nutritional status of pregnant women of some villages in Balasore district, Orissa. J Hum Ecol 20: 227-232.

6. Brien G, Davies M (2007) Nutrition knowledge and body mass index. Health Education Research 22: 571-575

7. Villar J, Merialdi M, Gülmezoglu A (2003) Nutritional interventions during pregnancy for the prevention or treatment of maternal morbidity and preterm delivery: an overview of randomized controlled trials. J Nutr 1335 suppl 2 : 1606S-1625S.

8. Nagiebs S (2003) Nutrition during maternity cycle. Review article, University of Assiut, Faculty of Nursing. P18-22.

9. UNICEF (2009) Maternal and Newborn Health in Nigeria: Developing Strategies to Accelerate Progress. The State of World's Children Pp. 19-22.

10. Mora J, Nestel $P(2000)$ Improving prenatal nutrition in developing countries: strategies, prospects, and challengers. American Journal of Clinical Nutrition 71: 1353s-1363s.

11. Wu G, Fuller W, Cudd T (2004) Maternal Nutrition and Fetal Development. J Nutr 134: 2169-2172.

12. Huffman S, Zehner E, Harvey P, Martin L, Piwoz E, et al. (2001) "Essential Health Sector Actions to Improve Maternal Nutrition in Africa".

13. AED LINKAGES (2004) Maternal Nutrition: Issues and Interventions; computer based slide presentation, by the Bureau for Global Health of the United States Agency for International Development (USAID), Updated August, 2004.

14. Latifa M Fouda, Manal H Ahmed, Nihal S Shehab (2012) Nutritional Awareness of Women during Pregnancy. Journal of American Science 8(7).

15. Naomi M (2010) Investigating health and nutrition messages given to pregnan women at bwaila hospital in Lilongwe. Akershus University College, Faculties of Health, Nutrition and Management.

16. Alice K, Christina A, Richard A (2012) Dietary Practices and Nutrient Intakes of Pregnant Women in Accra, Ghana. Current Research Journal Biological Sciences 4: 358-365.

17. Mitra M, Wan A, Manan W, Affizal A, Mohd S, et al. (2012) Dietary Knowledge and Behaviors in a Sample of Malay Pregnant Women. UMT 11th International Annual Symposium on Sustainability Science and Management 09th - 11th July 2012, Terengganu, Malaysia.

18. Painter J, Rah J, Lee Y (2003) Comparison of international food guide pictorial representation. J Am Diet Assoc 102: 483-489. 